\title{
Determine the Effect of Immunosuppressant on follicular regulatory T-cells in kidney transplant patients
}

\author{
MUJTABA ALI HASNAIN ${ }^{1}$, SAMRAH MUJTABA ${ }^{2}$, IQRA JAVED ${ }^{3}$, MISBAH $^{4}$, MUHAMMAD SHAHZAD GUL $^{5}$, ABDUL \\ GHAFFAR ${ }^{6}$ \\ ${ }^{1}$ Consultant Nephrologist/Assistant Professor of Medicine, Albany Medical College Albany New York USA. \\ ${ }^{2}$ Capital District Renal Physicians, Albany, New York USA. \\ ${ }^{4}$ M.phil Anatomy, Senior Demonstrator, Khawaja Muhammad Safdar Medical College Sialkot. \\ ${ }^{5}$ Nephrology Department Mayo Hospital, Lahore. \\ ${ }^{6}$ Medical Officer, DHQ Hospital Toba Tek Singh \\ Correspondence to Dr. Mujtaba Ali Hasnain Email: tamimrai18@gmail.com
}

\section{ABSTRACTS}

Background: Over the last few years, there are two major problems identified during organ transplantation such as surgical restrictions and transplant rejections. Few of these obstacles have been partially removed such as the use of immunosuppressant improved it consistently while decreasing graft rejection up to $12.2 \%$.

Methods: This study was conducted from 2019-2021. In all patients renal function was examined through glomerular filtration rate. Induction therapy was given to all the transplant recipients. Induction therapy with basiliximab $20 \mathrm{mg}$ intravenously on 0 and 4 days. After transplantation tacrolimus and MMF was given with varied concentration dose. Acute rejections were found in patients who had no biopsy or biopsy-proven rejection. In the end, clinical pathologists had analyzed all biopsies again and recipients who were experienced the vascular Banff grade 2 and tubule interstitial rejection.

Results: Immunosuppressant tacrolimus treated patients were $71(67.61 \%)$ and mycophenolate mofetil used in $34(32.38 \%)$. Total 39(37.14\%) rejections were received and 66(62.85\%) acceptance was recorded. Two types of rejection were highlighted namely cell-mediated rejection $25(23.80 \%)$ and $14(13.33 \%)$ chronic antibody-mediated rejection. The effect of tacrolimus on follicular helper $\mathrm{T}$ cells and follicular regulatory $\mathrm{T}$ cells shows the clear difference between the kidney transplant and healthy control cells. Reduction in numbers of follicular regulatory $T$ cells was measured in patients.

Conclusion: eventually we find tacrolimus significantly affects the number of follicular regulatory T-cells and follicular helper T cells. Alemtuzumab substantially lowers the follicular regulatory T-cells. Mycophenolate mofetil showed non-significant on T-cells.

Keywords: kidney transplant, follicular regulatory T-cells, follicular helper T-cells.

\section{INTRODUCTION}

Patients with chronic liver failure usually prefer kidney transplantation rather than hemodialysis or peritoneal dialysis. Because the majority of patients who are at the end-stage of renal disease found it as an optimal method of treatment than dialysis. Over the last few years, there are two major problems identified during organ transplantation such as surgical restrictions and transplant rejections ${ }^{12}$. Few of these obstacles have been partially removed such as the use of immunosuppressant improved it consistently while decreasing graft rejection up to $12.2 \%{ }^{13}$. On the other side chronic allograft rejections are an important barrier for long-term graft survival in order to lower the 45\%-55\% survival of kidney transplant patients.

The end-stage renal failure left only a single choice of kidney transplantation is now recognized by the international medical community. The improvement in the current immune detection mechanisms and upgraded immunosuppression have revamped the short-term outcomes of kidney transplantation. ${ }^{1}$ Although there are still deficits of evidence that show the effective methods for immune system function monitoring in patients after kidney transplant and massive leap lead blind spots in the clinical application of immunosuppressive agents ${ }^{2}$.

Received on 14-05-2021

Accepted on 27-09-2021
Graft rejection occurs at the low dose of immunosuppressant and inappropriate management causes the loss of the graft. On the other side a high dose of immunosuppressants can harm the patient's immune response, may lead to susceptibility to bacterial infections. Notably, infection is the leading cause of death in transplant patients ${ }^{3}$. It alters the status of the immune cell application of immunosuppressant's aid in the evaluation of immune status ${ }^{4}$.

It was noticed that increase in the proportion of $\mathrm{T}$ regulatory cells and $B$ cells producing IL-10 in peripheral blood of immune tolerant kidney transplant recipients ${ }^{5}$. So, immunosuppressive therapy was found helpful to assess the immune response to guide the further clinical diagnosis and treatment ${ }^{6}$.

The B-cell has a strong association with follicular $\mathrm{T}$ helper cells as colocalization occurs with B cells in the germinal center and activates the b-cells to differentiate plasma for the production of antibodies. ${ }^{7}$ Follicular regulatory $T$ cells control the response of the immune system $^{8}$ and regulate the costimulatory molecule CD86 on $B$ cells, giving rise to interleukin-10 and mediating cytolysis. Follicular regulatory $\mathrm{T}$ cells also show a transcription factor Helios and a marker to increase immunosuppressive functions $^{9}$. The dynamic balance between follicular regulatory $T$ cells and follicular helper $T$ cells is indispensable for immune homeostasis especially in patients with auto-immune disease ${ }^{10}$. 
The immunosuppressant namely calcineurin inhibitor (CNI) tacrolimus, reduces the number of impaired follicular helper and regulatory cells ${ }^{11}$. Moreover, it is still not clear that to what extent immunosuppressants affect the composition of both follicular helper and follicular regulatory cells ${ }^{1}$.

\section{MATERIAL AND METHOD}

This study was conducted from 2019-2021 after approval from IRB. In all patient's renal function was examined through glomerular filtration rate. Induction therapy was given to all the transplant recipients. Induction therapy with basiliximab 20mg intravenously on 0 and 4 days. Before the two weeks of transplant tacrolimus $0.1 \mathrm{mg} / \mathrm{kg}$, and mycophenolate mofetil (MMF) $1,000 \mathrm{mg}$, were given to patients. After transplantation tacrolimus and MMF was given with varied concentration dose. Acute rejections were found in patients who had no biopsy or biopsy-proven rejection. In the end, clinical pathologists had analyzed all biopsies again and recipients who were experienced the vascular Banff grade 2 and tubule interstitial rejection. They were receiving the methylprednisolone for 3 days as firstline therapy. Whereas patients treated with alemtuzumab received severe rejections ${ }^{14-15}$. All the cases in our study were treated with the above-mentioned doses of immunosuppressants.

Flow cytometry: To calculate the absolute numbers and subpopulation of follicular helper $\mathrm{T}$ cells and follicular regulatory $T$ cells fresh sample of peripheral blood up to 6$7 \mathrm{ml}$ in a heparin tube was collected. Sample can be stored at ambient temperature on a tuber-roller and used within two hours. Ficoll gradient medium was used to separate the mononuclear cells and intracellular staining of peripheral blood mononuclear cells was carried out through the monoclonal antibodies: anti-CD3 BV510 (OKT3, Biolegend, San Diego, CA).

Statistically analyses: Statistical calculation was carried out by IBM SPSS version 23. The comparison between two groups was executed using the U-test and for more than three groups Kruskal Wallis test was preferred. A P-value less than 0.05 is considered significant.

\section{RESULTS}

The obtained results depicts that $67.6 \%$ patients were male and $32.2 \%$ was female. All the patients receiving their first kidney transplant from donor of average age up to 55 years. The average age of all participant were 47 years. Patients with other diseases included $36(34.2 \%)$ diabetes mellitus, focal segmental glomerulosclerosis $7(6.66 \%)$, and unknown cases were 62(59.04\%) (Table 1).

Immunosuppressant tacrolimus treated patients were $71(67.61 \%)$ and mycophenolate mofetil used in $34(32.38 \%)$. Total 39(37.14\%) rejection were received and $66(62.85 \%)$ acceptance was recorded. Two types of rejection were highlighted namely cell mediated rejection $25(23.80 \%)$ and $14(13.33 \%)$ chronic antibody mediated rejection (Table 2 ).

The effect of tacrolimus on follicular helper T cells and follicular regulatory $T$ cells shows the clear difference between the kidney transplant and healthy control cells. Reduction in number of follicular regulatory $T$ cells was measured in patients. On the other hand no substantial difference was measured for follicular helper $T$ cells for both patients and healthy person. Mycophenolate mofetil exhibit the non-significant association with T-cells.

Table 1: General characteristics of participant $(n=105)$

\begin{tabular}{|l|l|}
\hline Characteristics & $\mathbf{n} \%$ \\
\hline Age median (range) & $47(26-60)$ \\
\hline Gender & $34(32.2 \%)$ \\
\hline Female & $71(67.6 \%)$ \\
\hline Male & $36(34.2 \%)$ \\
\hline Other diseases & $7(6.66 \%)$ \\
\hline Diabetes mellitus & $62(59.04 \%)$ \\
\hline Focal segmental glomerulosclerosis & $55(20-59)$ \\
\hline Unknown &
\end{tabular}

Table 2: Patients outcomes who received treatment. $n=105$

\begin{tabular}{|l|l|l|}
\hline Immunosuppressant & \%age & P value \\
\hline Tacrolimus & $71(67.61 \%)$ & 0.03 \\
\hline Mycophenolate mofetil & $34(32.38 \%)$ & 0.06 \\
\hline Rejection & $39(37.14 \%)$ & 0.02 \\
\hline Yes & $66(62.85 \%)$ & 0.03 \\
\hline No & $25(23.80 \%)$ & 0.03 \\
\hline Type of rejections & 0.02 \\
\hline Cell-mediated rejection & $14(13.33 \%)$ & \\
\hline $\begin{array}{l}\text { Chronic antibody mediated } \\
\text { rejection }\end{array}$
\end{tabular}

\section{DISCUSSION}

In the current study we have determined immunosuppressant effects on follicular regulatory cells in kidney transplant recipient. We concluded that tacrolimus based immunosuppression lowering the actual number of follicular regulatory $\mathrm{T}$ cells as compared to healthy person. There was no affect found on follicular helper $T$ cells. A study about the renal transplantation illustrated that elevated level of follicular regulatory cell before formation of donor-specific antibodies and had connection with antibody mediated rejection ${ }^{16}$. Furthermore, falling off follicular regulatory $\mathrm{T}$ cells was demonstrated in kidney transplant tissue and peripheral blood of recipient with anti-biotic mediated rejection ${ }^{17}$. Iymphocyte proliferation was inhibited by Mycophenolate mofetil as well as adverse effects of calcineurin as an inhibitor on function and differentiation of T-cells ${ }^{18-19}$. Although treatment with alemtuzmab had substantially lowered the number of total follicular regulatory as well as follicular helper $T$ cells. T-cells reproduction take place through clonal expansion after the administration of alemtuzumab that is opposed by thymopoiesis in procedure called homeostatic proliferation ${ }^{20}$. A study demonstrated that alemtuzumab used in treatment shows the impairment of homeostatic proliferation of follicular regulatory T-cells ${ }^{22}$. Another study attempted that regulatory $\mathrm{T}$ cell had potent association with transplant recipient outcomes and immunosuppressive drugs had strong impact on frequency of $T$ cells subsets. More inspection is required to explain the detail effect of these drugs on $T$ cells of immune system involved in processes of transplantation ${ }^{21}$. 


\section{CONCLUSION}

In this study we concluded that tacrolimus significantly affect the number of follicular regulatory T-cells and follicular helper $\mathrm{T}$ cells. Alemtuzumab substantially lower the follicular regulatory T-cells. Mycophenolate mofetil showed non-significant on T-cells.

\section{Conflict of interest: Nil}

\section{REFERENCES}

1. Galliford J, Game DS.Modern renal transplantation: present challenges and future prospects. PostgradMed J (2009) 85:91-101.

2. Liu Y, Hu J, Liu D, Zhou S, Liao J, Liao G, et al. Single-cell analysis reveals immune landscape in kidneys of patients with chronic transplant rejection. Theranostics (2020) 10:8851-62.

3. Liu Y, Zhou S, Hu J, Xu W, Liu D, Liao J, et al. Characterization of aberrant pathways activation and immune microenviroment of BK virus associated nephropathy. Aging (Albany NY) (2020) 12:14434-51.

4. Papp G, Boros P, Nakken B, Szodoray P, Zeher M. Regulatory immune cells and functions in autoimmunity and transplantation immunology. Autoimmun Rev (2017) 16:43544.

5. Becker LE, de Oliveira Biazotto F, Conrad H, Kinm LP, Gross-Weissmann ML, Waldherr R, et al. Cellular infiltrates and NFkB subunit c-Rel signaling in kidney allografts of patients with clinical operational tolerance. Transplantation (2012) 94:729-37.

6. Nova-Lamperti E, Chana P, Mobillo P, Runglall M, Kamra Y, McGregor R. Increased CD40 Ligation and Reduced BCR Signalling Leads to Higher IL-10 Production in B Cells From Tolerant Kidney Transplant Patients. Transplantation (2017) 101:541-7.

7. Fazilleau N, Mark L, McHeyzer-Williams LJ, McHeyzerWilliams MG. Follicular helper T cells: lineage and location. Immunity. (2009) 30:324-35.

8. Wing JB, Tekguc M, Sakaguchi S. Control of germinal center responses by T-follicular regulatory cells. Front Immunol. (2018) 9:1910.

9. Linterman MA, Pierson W, Lee SK, Kallies A, Kawamoto S, Rayner TF, et al. Foxp3+ follicular regulatory T cells control the germinal center response. Nat Med. (2011) 17:975-82.

10. Xu B, Wang S, Zhou M, Huang Y, Fu R, Guo C, et al. The ratio of circulating follicular $T$ helper cell to follicular $T$ regulatory cell is correlated with disease activity in systemic lupus erythematosus. Clin immunol. (2017) 183:46-53.
11. Wallin EF, Hill DL, Linterman MA, Wood KJ. The calcineurin inhibitor tacrolimus specifically suppresses human $t$ follicular helper cells. Front Immunol. (2018) 9:1184.

12. G. M. Fleming, "Renal replacement therapy review: past, present and future," Organogenesis, vol. 7, no. 1, pp. 2-12, 2014.

13. A. Hart, J. M. Smith, M. A. Skeans et al., "OPTN/SRTR 2017 annual data report: kidney," American journal of transplantation, vol. 19, Suppl 2, pp. 19-123, 2019.

14. Sablik KA, Clahsen-van Groningen MC, Looman CWN, Damman J, vanAgteren M, Betjes MGH. Treatment with intravenous immunoglobulins and methylprednisolone may significantly decrease loss of renal function in chronic-active antibody-mediated rejection. BMC Nephrology. (2019) 20:218.

15. van den Hoogen MWF, Hesselink DA, van Son WJ, Weimar W, Hilbrands LB. Treatment of steroid-resistant acute renal allograft rejection with alemtuzumab. Am J Transpl. (2013) 13:192-6.

16. Chenouard A, Chesneau M, Bui Nguyen L, Le Bot S, Cadoux $M$, Dugast $E$, et al. Renal operational tolerance is associated with a defect of blood Tfh cells that exhibit impaired $b$ cell help. Am J Transplant. (2017) 17:1490 501.

17. Chen W, Bai J, Huang $\mathrm{H}$, Bi L, Kong X, Gao Y, et al. Low proportion of follicular regulatory $\mathrm{T}$ cell in renal transplant patients with chronic antibodymediated rejection. Sci Rep. (2017) 7:1322.

18. Allison AC, Eugui EM. Mycophenolate mofetil and its mechanisms of action. Immunopharmacology. (2000) 47:85118.

19. Zeiser R, Nguyen VH, Beilhack A, Buess M, Schulz S, Baker $\mathrm{J}$, et al. Inhibition of CD4+CD25+ regulatory T-cell function by calcineurin-dependent interleukin-2 production. Blood. (2006) 108:390-9.

20. Bouvy AP, Klepper M, Betjes MG, Weimar W, Hesselink DA, Baan CC. Alemtuzumab as antirejection therapy: T cell repopulation and cytokine responsiveness. Transplant Direct. (2016) 2:e83.

21. Shahi, A., Salehi, S., Afzali, S., Gol Mohammad Pour Afrakoti, L., Esmaeili, M., Bagherpour, F., ... \& Amirzargar, A. A. (2021).

22. Evaluation of thymic output and regulatory $T$ cells in kidney transplant recipients with chronic antibody-mediated rejection. BioMed Research International, 2021. Macedo C, Walters JT, Orkis EA, Isse K, Elinoff BD, Fedorek SP, et al. Long-term effects of alemtuzumab on regulatory and memory Tcell subsets in kidney transplantation. Transplantation. (2012) 93:813-21. 